\title{
DIAPHYSEAL NUTRIENT FORAMINA OF RADII AND ULNAE: ANATOMICAL STUDY
}

\author{
Vijayalakshmi S. B', Sneha Guruprasad Kalthur'2, Antony Sylvan D'Souza ${ }^{3}$
}

${ }^{1}$ Assistant Professor, Department of Anatomy, RAK College of Medical Sciences, Ras Al-Khaimah, UAE.

2 Professor and HOD, Department of Anatomy, Kasturba Medical College, Manipal, India.

${ }^{3}$ Professor and Associate Dean, Department of Anatomy, Kasturba Medical College, Manipal, India.

\begin{abstract}
BACKGROUND

Bone is a highly vascular mineralised connective tissue, which performs numerous vital functions in the human body. The diaphyseal nutrient artery is the main source of blood to a long bone especially during its active growth period and the early stages of ossification. These arteries usually penetrate the cortex obliquely through the nutrient foramina, which leads into nutrient canals. The number, position, and direction of nutrient foramina vary in long bones of upper and lower limbs. The purpose of this research is to study the variation in diaphyseal nutrient foramina of forearm bones. Knowledge of the location, number, and direction of the Nutrient Foramina (NF) in the humerus is not only important in understanding the physiology of development of bone, but also are of significance in healing of fractured bones and orthopaedic surgeries.
\end{abstract}

\section{MATERIALS AND METHODS}

The present study was conducted on 100 forearm long bones of the upper limb to study the variation in nutrient foramen with respect to their number, location, direction, and size of the diaphyseal nutrient foramina.

\section{RESULTS}

In radius, the location of the nutrient foramen was in middle one-third of the bone (Between $17 \%$ and $49 \%$ ). In ulna, majority of the foramina were on the middle one-third between $26 \%$ and $48 \%$ of the total length. In both radius and ulna, most common position was on the anterior surface all directing towards the proximal end and with dominant foramen of large size.

\section{CONCLUSION}

An accurate knowledge of the location of the nutrient foramina in long bones can be useful in certain surgical procedures: in bone grafting, in microsurgical vascularised bone transplantation, and in many fractures.

\section{KEYWORDS}

Dominant Nutrient Foramina, Diaphyseal Nutrient Artery, Radii and Ulnae.

HOW TO CITE THIS ARTICLE: Vijayalakshmi SB, Kalthur SG, D'Souza AS. Diaphyseal nutrient foramina of radii and ulnae: anatomical study. J. Evolution Med. Dent. Sci. 2016;5(58):4031-4037, DOI: 10.14260/jemds/2016/922

\section{INTRODUCTION}

Bone is a connective tissue characterised by a vascular mineralised extracellular matrix, which produces an extremely hard tissue capable of providing support and protection. Apart from its role in movement of the body parts and body postures, it is the major site where minerals like calcium and phosphates are stored.[1]

Bone tissue which is the structural component of bones is classified as compact and spongy. The shaft of a long limb bone consists of an outer shell of compact bone within which is contained the hollow medullary cavity. At each end of the bone, the cavity is occupied by cancellous tissue, which constitutes the sites of red marrow that produces red blood cells (RBC), white blood cells (WBC), and platelets.[2]

Long bones receive blood from three systems (sources): nutrient artery, metaphyseal-epiphyseal, and periosteal. The diaphyseal nutrient artery is the main source of blood to a long bone especially during its active growth period and the early stages of ossification. ${ }^{3}$

Financial or Other, Competing Interest: None.

Submission 26-04-2016, Peer Review 08-07-2016,

Acceptance 13-07-2016, Published 21-07-2016.

Corresponding Author:

Dr. Vijayalakshmi S.B,

Shivanugraha, Mairkome,

Mandarthi-576223

Udupi, Karnataka.

E-mail: drvijishetty@gmail.com

DOI: $10.14260 /$ jemds/2016/922
Nutrient arteries branch from the major systemic arteries, enter the diaphyseal cortex through the nutrient foramen and then enter the medullary canal branching into ascending and descending small arteries. The site of entry and the angle with which the nutrient artery enters the bone are almost constant and characteristically directed away from the dominant growing epiphysis. The entire osteal tissue and bone marrow of the long bones are supplied by nutrient arteries. ${ }^{[4]}$ Bone blood flow is the major determinant of fracture healing. Injury to the nutrient artery at the time of fracture or during subsequent manipulation and surgery maybe a significant predisposing factor to faulty union of long bones.

The nutrient foramina are openings in the bone that conduct the nutrient arteries and the peripheral nerves to reach the marrow. The shaft of every long bone bears one or more nutrient foramina, which are generally obliquely placed which is thought to be due to unequal growth at the upper end and lower epiphysis. The artery gets dragged in the direction of more rapid growth and the direction of slope of entry of the nutrient foramen therefore points away from the growing end of the bone. In general, the direction of nutrient foramina in the long bones of human limbs is described as being directed towards the elbow and away from the knee.

The greatest numbers of nutrient foramina are found in the diaphysis and epiphysis. The number, position, and direction of nutrient foramina vary in long bones of upper and lower limbs. In the radius, generally, there is one nutrient 
diaphyseal foramen located on the anterior surface of the bone and directed proximally towards the elbow. In the ulna, also usually one, but occasionally two major nutrient diaphyseal foramina are located on the anterior surface, which are directed proximally towards the elbow.[5] Anterior interosseous artery, a branch of ulnar artery gives nutrient branches to radius and ulna.

Knowledge of the location, number, and direction of the Nutrient Foramina (NF) in the long bones of the limbs is not only important in understanding the physiology of development of long bones, but also are of significance in healing of fractured bones and orthopaedic surgeries. These parameters may vary depending on the human race and their geographical distribution. The present investigation is planned to study the location, number, and direction of the nutrient foramen in long bones of adult forearm, i.e. radius and ulna.

\section{MATERIALS AND METHODS}

The study was conducted on 100 human forearm long bones preserved in Department of Anatomy, Kasturba Medical College, Manipal, Manipal University. Forearm long bones of both right and left sides were included in the study. All bones were from adults ( $>20$ years) and were of unknown sex. A prior approval was obtained from the Institutional Ethics Committee to conduct the study.

\section{The Following Forearm Long Bones were Included in the} Study:

- $\quad$ Radius - 50 (26 right side, 24 left side).

- Ulna - 50 (21 right side, 29 left side).

\section{PARAMETERS}

\section{Non-metrical parameters}

- Number of nutrient foramina - The number of diaphyseal nutrient foramina were observed in all bones with the help of a hand lens. In bones having more than one foramen, the larger sized foramen was recorded as the Dominant Foramen (DF) and the other smaller as Secondary Foramen (SF). Only diaphyseal foramina were considered and foramina at the ends of bone were ignored. Diaphyseal foramina exhibited distinct grooves proximal to and around the margins with adjacent canals slightly raised above the surface of rest of the bone.

- Direction and obliquity - The foramina which are obliquely placed were considered;

- Position - It was described into horizontal and vertical zones.

Horizontal zone - was with respect to surface and border. Any foramen lying within $1 \mathrm{~mm}$ from any border was taken to be lying on that border.[6]

Vertical zone - was with respect to length of the bone, which was divided into three zones that is upper one-third, middle one-third, and lower one-third.

- Caliber - Three hypodermic needles with caliber of 20G, $24 \mathrm{G}$, and $26 \mathrm{G}$ were used to determine the caliber of foramina.[7]

\begin{tabular}{|c|c|}
\hline Caliber of the Needle & Size of the Foramina \\
\hline $20 \mathrm{G}$ & Large size \\
\hline $24 \mathrm{G}$ & Medium size \\
\hline $26 \mathrm{G}$ & Small size \\
\hline$>20 \mathrm{G}$ & Very large size \\
\hline$<26 \mathrm{G}$ & Very small size \\
\hline
\end{tabular}

\section{METRICAL PARAMETERS}

\section{Total Length}

The total length of the bone was measured using osteometric board. The longest length of the bone was considered for each long bone as described below.

\begin{tabular}{|c|c|}
\hline Bones & Total Length \\
\hline Radius & $\begin{array}{c}\text { Greatest length between the most proximal point on } \\
\text { the margin of the head and tip of the styloid } \\
\text { process. }\end{array}$ \\
\hline Ulna & $\begin{array}{c}\text { Distance between the highest point of olecranon } \\
\text { and deepest point of the styloid process. }\end{array}$ \\
\hline
\end{tabular}

Distance of the nutrient foramina from the proximal end of the bone, distal end, and also from the mid shaft was measured using digital Vernier caliper.[6]

Foraminal index (FI) (Hughes et al., 1952) - The FI was calculated by using the formula, $\mathrm{FI}=(\mathrm{DNF} * \mathrm{TL}) / 100$, where DNF is the distance from the proximal end of the bone to the nutrient foramen and TL is the total bone length.

Circumference of the bone at the level of nutrient foramen was noted with a help of a wire and measured using Vernier caliper.

\section{STATISTICAL ANALYSIS}

Data analysed using SPSS Software.

- Total length of bones were expressed as Mean \pm SD.

- Foraminal Index (FI) - Mean FI \pm SD.

- Distance of the NF from the proximal end [DNF (p)] Mean DNF (p) \pm SD.

- Distance of the NF from the distal end [DNF (d)] - Mean DNF (d) \pm SD.

- Distance of the NF from the mid-shaft - Mean mid shaft \pm SD.

- Circumference of the bone at the level of the NF - Mean circumference \pm SD.

\section{RESULTS}

In the present study, adult forearm long bones were analysed. Variations in number, size of the foramen, direction of foramen, and their location were recorded.

\section{Variation in the Number of Nutrient Foramina}

The variations in the number of nutrient foramina was assessed in 100 forearm long bones, which included 50 radii and 50 ulnae of right and left sides [Table 1].

\section{Radii}

Among 50 radii analysed in the study, single nutrient foramen was observed in $90 \%$ of the bones while $8 \%$ of the bones did not have any nutrient foramen. The frequency of finding radii with two nutrient foramina was very rare $(2 \%)$. However, none of the bones had more than two nutrient foramina.

When the variations in the number was analysed separately in radii of right and left side, it was observed that frequency of bones having no nutrient foramen was higher on the left side ( 3 bones) compared to radii of right side ( 1 bone) 
[Figure 1]. But, the number of radii with single nutrient foramen was higher on the right side (25 on right and 20 on left). Only one radii of left side had two nutrient foramina in it.

\section{Ulnae}

Frequency of observing single nutrient foramen was highest in ulna. Among 50 bones, 48 ulnae (96\%) had single nutrient foramen. Two nutrient foramina were observed in one ulna $(2 \%)$ and in one ulna there was no nutrient foramen. Out of 48 ulnae which had single nutrient foramen, 21 ulnae was of the right side and 27 were of left side. Both ulnae with two nutrient foramina and ulna without any nutrient foramen were of left side [Figure 2].

\section{Directions of Nutrient Canal in Forearm Long Bones}

The direction of nutrient canal was observed in 100 forearm long bones [Table 2]. In 50 radii of both right and left side together, total of 47 nutrient foramina were observed all of which were directed towards the proximal end. Similarly, in 50 ulnae of both the sides, there were 50 nutrient foramina in total all of which were directed towards the proximal end.

\section{Location of Nutrient Foramen in Radius and Ulna Radii (n=50)}

In 50 radii of right and left side, a total of 47 nutrient foramina were found. No nutrient foramen was observed on the posterior border, posterior surface, or the lateral surface [Table 3]. Majority of the nutrient foramina (34) were observed on the anterior surface (AS), which was seen in 33 radii [Figure 3]. Among these, 34 (72.3\%) foramina, 33 were dominant and 1 was secondary. In 8 bones, there were a total of 8 nutrient foramina $(17 \%)$ on the anterior border $(\mathrm{AB})$ all of which were dominant. In 5 bones, on the Intermediate Border (IB), total of 5 nutrient foramina (10.6\%) were observed all of which were dominant. In addition, 4 (8\%) radii out of 50 had no foramen [Table 3].

\section{Ulnae $(n=50)$}

In 50 ulnae of both right and left sides, there were total of 50 nutrient foramina [Table 3]. On posterior border (PB), posterior surface (PS), and medial surface (MS), ulnae of the study group did not have any nutrient foramen. In 41 bones, a total of 42 nutrient foramina (84\%) were observed on the anterior surface among which 41 were dominant and 1 was secondary foramen [Figure 4]. In 4 bones anterior border (AB) and in other 4 bones intermediate border (IB) had 4 nutrient foramina each of dominant group.

\section{Position of Nutrient Foramen in Forearm Long Bones Divided into Vertical Zones}

The forearm long bones were divided into three equal halves and designated as upper $1 / 3^{\text {rd }}$, middle $1 / 3^{\text {rd }}$, and lower $1 / 3^{\text {rd }}$.

\section{Radii}

In 50 radii of both right and left sides, a total of 47 nutrient foramina were observed. In upper $1 / 3$ of the bone, there were 19 nutrient foramina (10 on right side and 9 on left side) [Table 4]. On the right side, out of 10 nutrient foramina, 4 were found on the anterior border, 1 on the intermediate border, and 5 on anterior surface. Whereas, on the left side, out of 9 nutrient foramina, 2 were found on the anterior border and 7 were on the anterior surface. Majority of the nutrient foramina (28 out of 47 ) were found in the middle $1 / 3^{\text {rd }}$ of the bone [Figure 5]. Out of 15 foramina on the right side, 1 was on the anterior border, 2 were on the intermediate border, and 12 were on the anterior surface. Similarly, among 13 foramina on the left side, 1 was on the anterior border, 2 were on the intermediate border, and 10 were on the anterior surface. No nutrient foramina were found in the lower $1 / 3^{\text {rd }}$ of the bone.

\section{Ulnae}

In 50 ulnae, a total of 50 nutrient foramina were observed. In upper $1 / 3^{\text {rd }}$ of the bone of right side, there were 9 nutrient foramina while on the left side there were 11 nutrient foramina [Table 5]. On the anterior border of the right side ulna, there was one nutrient foramen and 8 were observed on the anterior surface of the upper $1 / 3^{\text {rd }}$ of the bone. On the left, all the 11 foramina were observed on the anterior surface [Figure 5]. In the middle $1 / 3^{\text {rd }}$ of the bone, there were 30 nutrient foramina (12 on right side and 18 on left side ulnae); on the anterior border, 3 nutrient foramina ( 1 on right side and 2 on left side); on intermediate border, 4 nutrient foramina ( 2 on each side); and on anterior surface, 23 nutrient foramina ( 9 on right side and 14 on left side) were observed in middle $1 / 3^{\text {rd }}$ of bone. No nutrient foramina were observed in lower $1 / 3^{\text {rd }}$ of the bone.

\section{Variations in the Size of Nutrient Foramina in Forearm Long Bones}

Different sizes of nutrient foramina ranging from very small to very large were observed in the forearm long bones. Only dominant foramina caliber was noted.

\section{Radii}

In 50 radii, only 47 nutrient foramina were present in total out of which $22(46.8 \%)$ had large-calibered foramina followed by 18 (38.3\%) medium-sized caliber, 5 (10.9\%) of small-sized caliber, and only $1(2.1 \%)$ with very small-caliber foramen (Figure 6). 22 radii had large-calibered dominant foramina, 18 radii had medium-sized caliber, 5 of them had small, and 1 radius had dominant foramen of very small caliber [Table 6].

\section{Ulnae}

Total of 50 foramina were observed in the ulnae of right and left sides together. Among these, 49 (98\%) dominant foramina, $32(65.3 \%)$ were of large-sized caliber, $8(16.3 \%)$ were with medium, $5(10.2 \%)$ were with small, and $4(8.2 \%)$ were of very small caliber [Figure 7]. Altogether, out of 50 bones, 32 were of large-sized caliber, 8 of medium-sized caliber, 5 and 4 radii of small and very small caliber respectively [Table 7].

\section{Metrical Parameters of Forearm Long Bones [Table 8]}

In radius, the mean length was $23 \mathrm{~cm}$. The distance of NF from proximal end was $8.1 \mathrm{~cm}$, from distal end was $14.8 \mathrm{~cm}$, and from mid shaft was about $3.5 \mathrm{~cm}$ above or below. The mean FI - 34.9 and mean circumference was $4.35 \mathrm{~cm}$.

The mean length in ulna was $26.6 \mathrm{~cm}$. The presence of NF from the proximal end was $9.5 \mathrm{~cm}$ and $16.4 \mathrm{~cm}$ from distal end. About $3.5 \mathrm{~cm}$ above or below the mid length was the presence of NF on an average. The mean FI - 35.9 and mean circumference was $5.1 \mathrm{~cm}$. 


\begin{tabular}{|c|c|c|c|c|}
\hline \multirow{2}{*}{ Bones } & $\begin{array}{c}\text { Number of } \\
\text { Foramen }\end{array}$ & $\begin{array}{c}\text { Right } \\
\text { Side }\end{array}$ & $\begin{array}{c}\text { Left } \\
\text { Side }\end{array}$ & $\begin{array}{c}\text { Total } \\
\text { Number }\end{array}$ \\
\hline \multirow{2}{*}{$\begin{array}{c}\text { Radius } \\
(\mathrm{n}=50)\end{array}$} & 0 & 1 & 3 & 4 \\
\cline { 2 - 5 } & 1 & 25 & 20 & 45 \\
\hline \multirow{2}{*}{$\begin{array}{c}\text { Ulna } \\
(\mathrm{n}=50)\end{array}$} & 2 & 0 & 1 & 1 \\
\cline { 2 - 5 } & 0 & 0 & 1 & 1 \\
\cline { 2 - 5 } & 2 & 21 & 27 & 48 \\
\hline
\end{tabular}

\begin{tabular}{|c|c|c|c|}
\hline Bones & $\begin{array}{c}\text { Total No. of } \\
\text { Foramina }\end{array}$ & $\begin{array}{c}\text { Towards } \\
\text { Proximal End }\end{array}$ & $\begin{array}{c}\text { Towards } \\
\text { Distal End }\end{array}$ \\
\hline $\begin{array}{c}\text { Radius } \\
(\mathrm{n}=50)\end{array}$ & 47 & 47 & 0 \\
\hline $\begin{array}{c}\text { Ulna } \\
(\mathrm{n}=50)\end{array}$ & 50 & 50 & 0 \\
\hline
\end{tabular}

Table 2: Various Directions of the Nutrient Canal Observed in the Forearm Long Bones

Table 1: Variations in Number of Nutrient Foramina Observed in Forearm Long Bones

\begin{tabular}{|c|c|c|c|c|c|}
\hline \multirow[t]{2}{*}{ Bone } & \multirow[t]{2}{*}{ No. of Bones (\%) } & \multirow[t]{2}{*}{ Location } & \multirow{2}{*}{$\begin{array}{c}\text { Total Number } \\
\text { of Foramina (\%) }\end{array}$} & \multicolumn{2}{|c|}{$\begin{array}{c}\text { Number of } \\
\text { Nutrient } \\
\text { Foramen }\end{array}$} \\
\hline & & & & $\begin{array}{c}\text { Dominant Foramen } \\
\text { (DF) }\end{array}$ & $\begin{array}{c}\text { Secondary Foramen } \\
\text { (SF) }\end{array}$ \\
\hline \multirow{6}{*}{$\begin{array}{c}\text { Radii } \\
(n=50) \\
T F=47\end{array}$} & $8(16 \%)$ & $\mathrm{AB}$ & $8(17 \%)$ & 8 & 0 \\
\hline & 0 & $\mathrm{~PB}$ & 0 & 0 & 0 \\
\hline & $5(10 \%)$ & IB & $5(10.6 \%)$ & 5 & 0 \\
\hline & $33(66 \%)$ & AS & $34(72.3 \%)$ & 33 & 1 \\
\hline & 0 & PS & 0 & 0 & 0 \\
\hline & 0 & LS & 0 & 0 & 0 \\
\hline \multirow{6}{*}{$\begin{array}{c}\text { Ulnae } \\
(n=50) \\
T F=50\end{array}$} & $4(8 \%)$ & $\mathrm{AB}$ & $4(8 \%)$ & 4 & 0 \\
\hline & 0 & PB & 0 & 0 & 0 \\
\hline & $4(8 \%)$ & IB & $4(8 \%)$ & 4 & 0 \\
\hline & $41(82 \%)$ & AS & $42(84 \%)$ & 41 & 1 \\
\hline & 0 & PS & 0 & 0 & 0 \\
\hline & 0 & MS & 0 & 0 & 0 \\
\hline
\end{tabular}

$\mathrm{AB}=$ Anterior border; $\mathrm{IB}=$ Intermediate border; $\mathrm{PB}=$ Posterior border; $\mathrm{AS}=$ Anterior surface; $\mathrm{LS}=$ Lateral surface; MS= Medial surface; PS= Posterior surface.

\begin{tabular}{|c|c|c|c|c|c|c|c|c|c|c|c|c|c|c|}
\hline \multirow[b]{2}{*}{ Vertical Zones } & \multicolumn{7}{|c|}{ Right Side } & \multicolumn{7}{|c|}{ Left Side } \\
\hline & $\stackrel{q}{q}$ & $\stackrel{n}{a}$ & $\cong$ & $\mathcal{z}$ & $\tilde{n}$ & 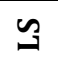 & Total & $\ddot{q}$ & $\stackrel{m}{2}$ & $\vartheta$ & 2 & $\check{a}$ & $\tilde{a}$ & Total \\
\hline Upper $1 / 3^{\text {rd }}$ & 4 & 0 & 1 & 5 & 0 & 0 & 10 & 2 & 0 & 0 & 7 & 0 & 0 & 9 \\
\hline Middle 1/3rd & 1 & 0 & 2 & 12 & 0 & 0 & 15 & 1 & 0 & 2 & 10 & 0 & 0 & 13 \\
\hline Lower $1 / 3^{\text {rd }}$ & 0 & 0 & 0 & 0 & 0 & 0 & 0 & 0 & 0 & 0 & 0 & 0 & 0 & 0 \\
\hline Total & 5 & $\mathbf{0}$ & 3 & 17 & $\mathbf{0}$ & $\mathbf{0}$ & 25 & 3 & $\mathbf{0}$ & 2 & 17 & $\mathbf{0}$ & $\mathbf{0}$ & 22 \\
\hline
\end{tabular}

$\mathrm{AB}=$ Anterior border; $\mathrm{PB}=$ Posterior border; $\mathrm{IB}=$ Intermediate border; $\mathrm{AS}=$ Anterior surface; $\mathrm{PS}=$ Posterior surface; $\mathrm{LS}=\mathrm{Lateral}$ surface.

\begin{tabular}{|c|c|c|c|c|c|c|c|c|c|c|c|c|c|c|}
\hline \multirow{2}{*}{$\begin{array}{c}\text { Vertical } \\
\text { Zones }\end{array}$} & \multicolumn{7}{|c|}{ Right side } & \multicolumn{7}{|c|}{ Left side } \\
\hline & $\sum$ & $\stackrel{n}{a}$ & $\vartheta$ & $\sum$ & $\tilde{n}$ & $\sum^{\infty}$ & Total & $\stackrel{m}{\alpha}$ & $\underline{a}$ & 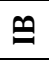 & $\sum$ & $n$ & $\sum^{\infty}$ & Total \\
\hline Upper $1 / 3^{\text {rd }}$ & 1 & 0 & 0 & 8 & 0 & 0 & 9 & 0 & 0 & 0 & 11 & 0 & 0 & 11 \\
\hline Middle $1 / 3^{\text {rd }}$ & 1 & 0 & 2 & 9 & 0 & 0 & 12 & 2 & 0 & 2 & 14 & 0 & 0 & 18 \\
\hline Lower $1 / 3^{\text {rd }}$ & 0 & 0 & 0 & 0 & 0 & 0 & 0 & 0 & 0 & 0 & 0 & 0 & 0 & 0 \\
\hline Total & 2 & $\mathbf{0}$ & 2 & 17 & $\mathbf{0}$ & $\mathbf{0}$ & 21 & 2 & $\mathbf{0}$ & 2 & 25 & $\mathbf{0}$ & $\mathbf{0}$ & 29 \\
\hline
\end{tabular}

$\mathrm{AB}=$ Anterior border; $\mathrm{PB}=$ Posterior border; $\mathrm{IB}=$ Intermediate border; $\mathrm{AS}=$ Anterior surface; $\mathrm{MS}=$ Medial surface; $\mathrm{PS}=\mathrm{Posterior}$ surface.

\begin{tabular}{|c|c|c|}
\hline \multirow{2}{*}{ Size of the Dominant Nutrient Foramina } & \multicolumn{2}{|c|}{ Combined (Right and Left) } \\
\cline { 2 - 3 } & No. of Bones & 1 \\
\hline Very small & 1 & 5 \\
\hline Small & 5 & 18 \\
\hline Medium & 22 & 22 \\
\hline Large & 18 & of Dominant Foramina \\
\hline \multicolumn{2}{|c|}{ Table 6: Size of the Nutrient Foramina in } \\
Radii of Right and Left Sides ( $\mathbf{n = 5 0 ,} \boldsymbol{T F = 4 7 )}$ \\
\hline
\end{tabular}




\begin{tabular}{|c|c|c|}
\hline \multirow{2}{*}{ Size of the Dominant Nutrient Foramina } & \multicolumn{2}{|c|}{ Combined (Right and Left) } \\
\cline { 2 - 3 } & No. of Bones & 4 \\
\hline Very small & 4 & 5 \\
\hline Small & 5 & 8 \\
\hline Medium & 8 & 32 \\
\hline Large & 32 & No. Dominant Foramina \\
\hline \multicolumn{2}{|c|}{ Table 7: Size of the Nutrient Foramina in Ulnae of Right and Left Sides (n=50, TF=50) }
\end{tabular}

\begin{tabular}{|c|c|c|c|c|c|c|}
\hline \multirow{2}{*}{ Bone } & \multicolumn{7}{|c|}{ Metrical Parameters in cm (Mean SE) } \\
\cline { 2 - 7 } & Length & DNF (p) & FI & DNF (d) & Mid-shaft & Circum \\
\hline Radius & $23.00 \pm 1.61$ & $8.10 \pm 1.43$ & $34.90 \pm 5.94$ & $14.80 \pm 1.67$ & $3.50 \pm 1.30$ & $4.35 \pm 0.28$ \\
\hline Ulna & $26.60 \pm 1.83$ & $9.50 \pm 1.50$ & $35.90 \pm 5.71$ & $16.40 \pm 2.06$ & $3.50 \pm 1.57$ & $5.10 \pm 0.40$ \\
\hline \multicolumn{7}{|c|}{ Table 8: Metrical Parameters of Forearm Long Bones } \\
\hline
\end{tabular}

DNF $(p)=$ Mean distance of NF from the proximal end;

$\mathrm{FI}=$ Foraminal index;

DNF $(d)=$ Mean distance from distal end;

Mean circum $=$ Mean circumference at the level of NF.

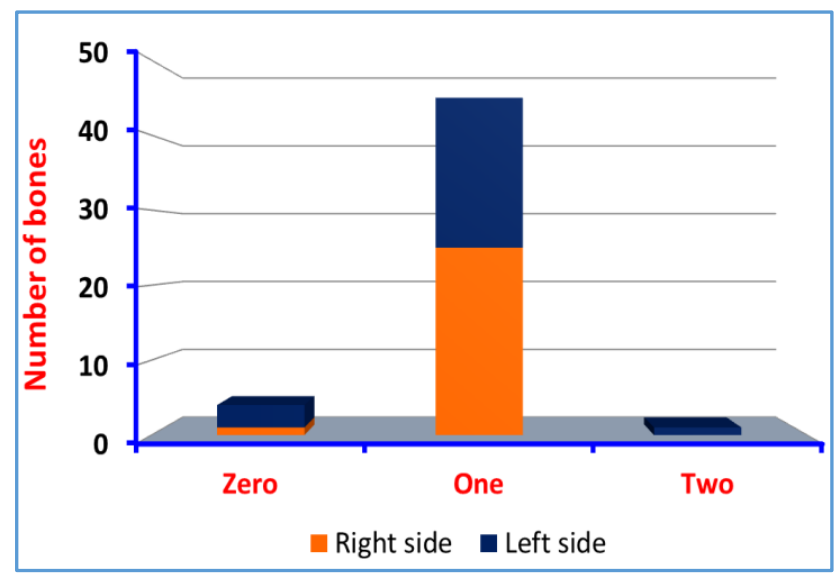

Fig. 1: Frequency of Variation in the Number of Nutrient Foramen in Radii of Right and Left Sides $(n=50)$

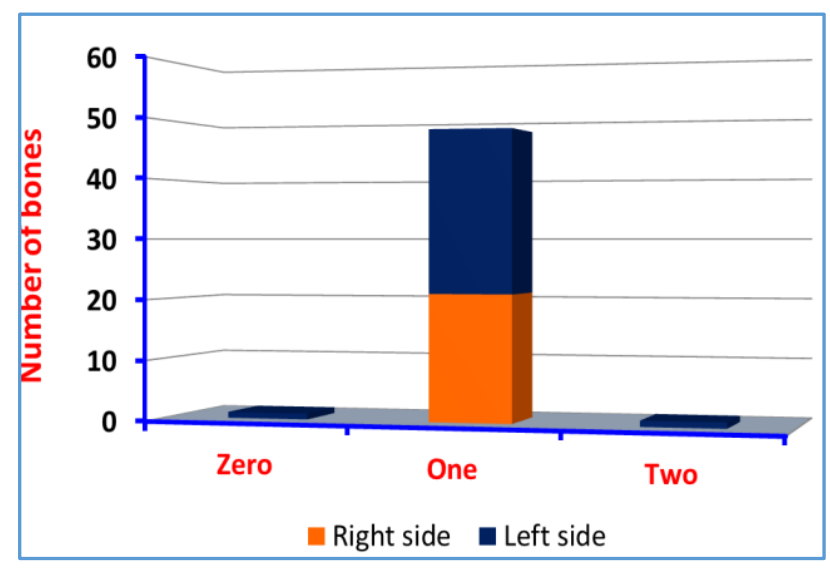

Fig. 2: Frequency of Variation in the Number of Nutrient Foramen in Ulnae of Right and Left Sides $(n=50)$

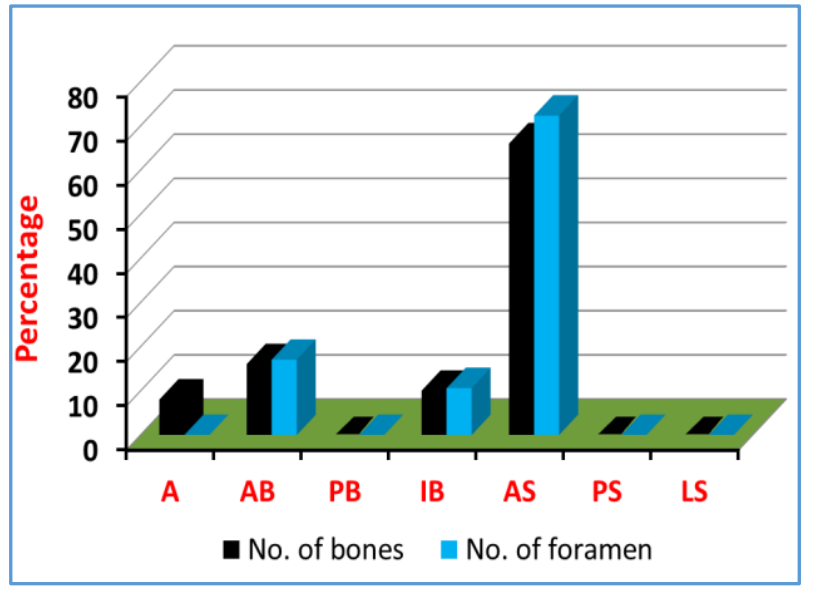

Fig. 3: Location of Nutrient Foramen in Radii of Right and Left Sides $(n=50)$

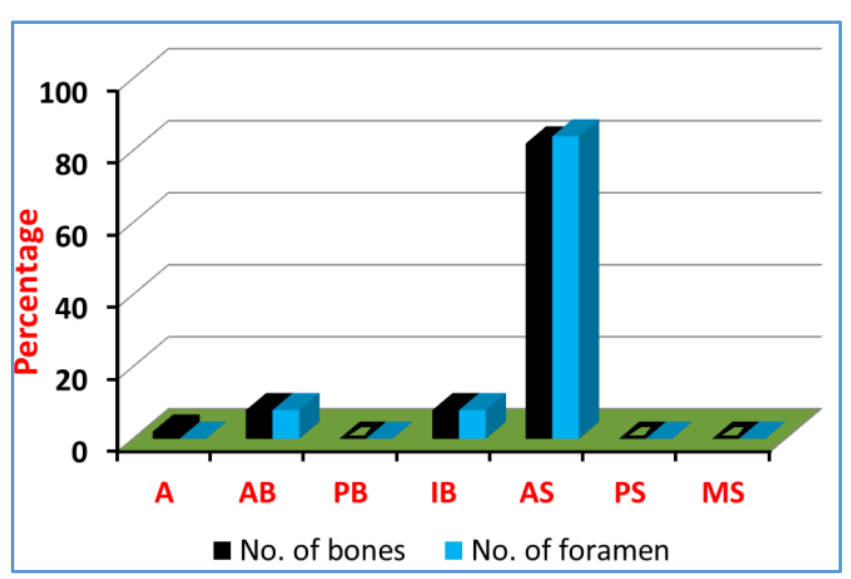

Fig. 4: Location of Nutrient Foramen in Ulnae of Right and Left Sides $(n=50)$ 


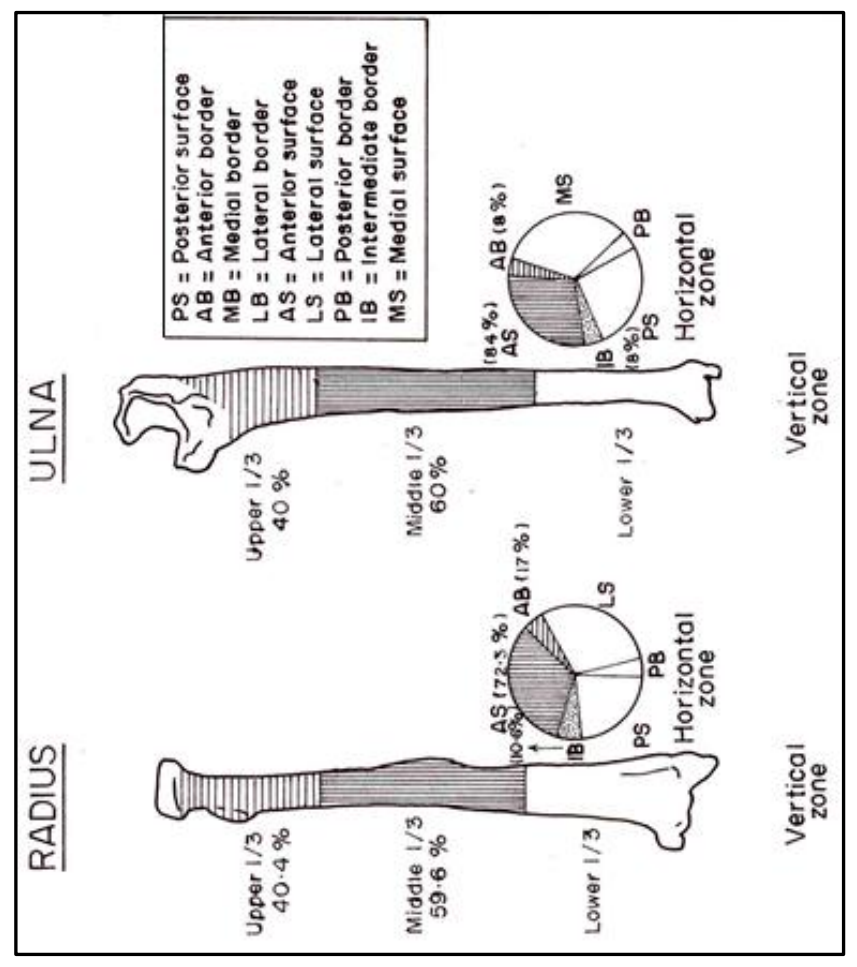

Fig. 5: Position of Nutrient Foramen in Forearm Long Bones

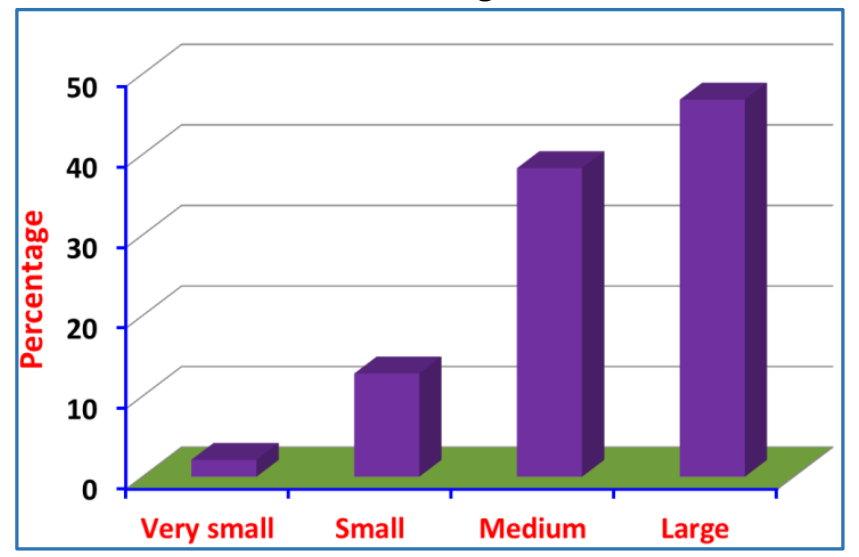

Fig. 6: Various Sizes of Nutrient Foramina Observed in Radii of Right and Left Sides Together $(n=50)$

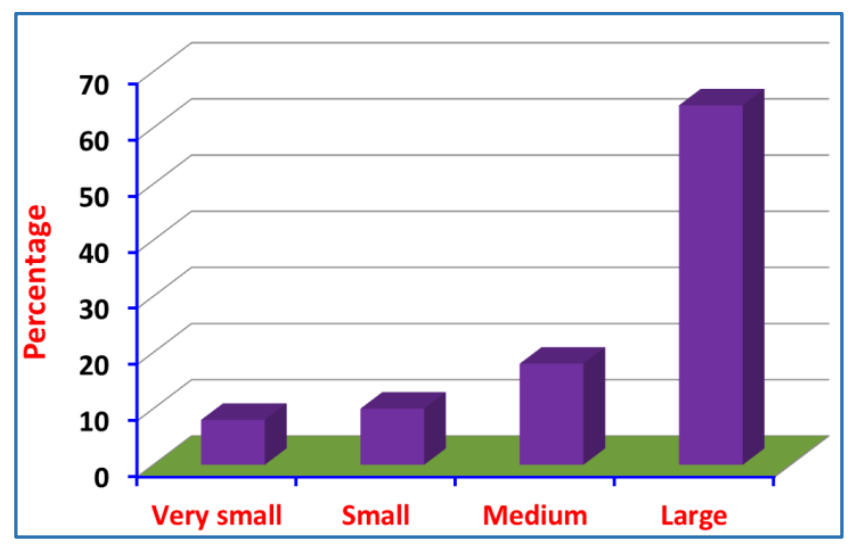

Fig. 7: Various Sizes of Nutrient Foramina Observed in Ulnae of Right and Left Sides Together $(n=50)$

\section{DISCUSSION}

\section{Radii}

In the present study, the mean length was $23 \pm 1.61 \mathrm{~cm}$ and was agreeing with the previous study by Kizilkanat et al (2007). The foraminal index of radii ranged from 17.09 to 48.66 in the present study. On the contrary, the previous study done by Kizilkanat et al 2007; Campos et al, 1987; and Mysorekar, 1967 reported FI range from as low as $22.2 \%$, $25.11 \%$, and $26.95 \%$ respectively. This difference may be due to different population group. The highest range of FI was in agreement with all.

In the present study, majority $90 \%$ of the radii had single nutrient foramen. This agrees with the earlier studies, which reported the incidence from $93.3 \%$ to $100 \%$.[6,8,9,10 and 11]

About $8 \%$ of radii did not have nutrient foramen in present study. Absence of NF in radii has been reported by previous studies.[6,10 and 11], but incidence was only to $1 \%$. $2 \%$ of the radii had two NF. This presence of double NF has been reported by Shulman (1959), Mysorekar (1967), Longia et al (1980), and Kizilkanat et al (2007) wherein Mysorekar (1967) had little high incidence of $4.4 \%$.

Regarding caliber $46.8 \%$ of NF were of large caliber in the present study, which was not in agreement with earlier reports. ${ }^{[9,10]}$ Medium-sized caliber were majority in number in the study conducted by Longia et al (1980) and Kizilkanat et al (2007), which was about $38.3 \%$ in the present study. $10.6 \%$ of NF were of small caliber, which was also not in agreement with the Longia et al, 1980 where the incidence was $24.5 \%$. Even in radius, it was observed about $2.1 \%$ of NF were of very small-sized caliber.

In the present investigation, the location of the nutrient foramina in radii on the vertical zone, $59.6 \%$ of NF were observed on the middle one-third, which was also found in the previous studies. Almost, $40 \% \mathrm{NF}$ were in upper onethird, which was agreeing with previous studies.[6,10 and 11] However, Longia et al (1980) observed few NF (1.96\%) on the lower one-third, which was not observed in the present study. Analysis of NF on the horizontal zone showed that the most common position was on the anterior surface, which agrees with earlier reports.[6,8,9,10and11] where Campos et al (1987) had almost $100 \%$. Few NF were also seen on the anterior border and intermediate border which agrees with the previous studies.[6and10] In the previous studies.[6,9and10] observed few NF on the posterior surface, which was not observed in present study. Also, the lateral surface in Kizilkanat et al (2007) study showed $41.5 \%$, but not to be present in our study. The posterior border in the study done by Shulman (1959) had 2\% foramina, but not to be seen in the present study. It was observed that in Turkish population. ${ }^{[9]}$ all the surfaces showed presence of foramen wherein present study done in Indian population only anterior surface had foramina.

\section{Ulnae}

Present investigation showed the mean length of ulna was $23 \pm 1.83 \mathrm{~cm}$, which was similar to the study done by Kizilkanat et al (2007). In the present study, FI ranges from 26.58 to $47.69 \%$. This almost agrees with the earlier reports. $[6,8$, and 9$] 96 \%$ of the ulnae had single nutrient foramen 
in the present study. The results of this study are similar to that reported by Shulman (1959), Mysorekar (1967), Longia et al (1980), Campos et al (1987), and Kizilkanat et al (2007). Absence of NF in ulna has been reported by earlier studies [13 and 16], which also observed in present study as $2 \%$. In addition, $2 \%$ of the ulna had double NF. Similar results have been reported by earlier studies.[6,8,9,10and11] But, the incidence of double foramina varied maybe due to different sample size and different population group. Longia et al (1980) reported ulna having three $\mathrm{NF}$, which was not observed in the present study.

Nutrient foramen of large caliber was in majority $64 \%$ in present study, which was not in agreement with previous reports.[9and10] They did not get any NF of large caliber, but had majority of medium size followed by small size. About $8 \%$ of the NF in the ulna was of very small-sized caliber.

In the ulnae, middle one-third was the commonest site for presence of NF in present study, which was in agreement with Shulman (1959) and Mysorekar (1967). The next common site was upper one-third, which was similar to studies done by.[6,10and11] In the lower one-third of the bone, there was no nutrient foramen in this study. On contrary, study done by Longia et al (1980) observed $0.9 \%$ of NF on lower one-third. Also, regarding to surfaces and borders, it was analysed that the most common position was anterior surface, which agrees with earlier reports.[6,8,9,10and11] Other surface like posterior surface had no NF, but was observed by previous authors.[9and10] Authors like Shulman (1959) and Kizilkanat et al (2007) also found NF on medial surface, but it was not observed in present study. The next site was intermediate border, which had $8 \%$, which was observed by.[6, 9, and 11] Also, anterior border had 8\% NF which was observed only in Indian studies done by Mysorekar (1967) and Longia et al (1980).

\section{CONCLUSION}

In conclusion, the nutrient foramen with respect to the location in the radii and ulnae, majority were on the middle third. Majority of foramina were on anterior surface all directing towards proximal end. Majority of the nutrient foramina in the radius and ulna were of large-sized caliber.
An accurate knowledge of the location of the nutrient foramina in long bones can be useful in certain surgical procedures: in bone grafting, in microsurgical vascularised bone transplantation and in many fractures. It helps to prevent intraoperative injuries in orthopaedic as well as in plastic and reconstructive surgery. Delayed or nonunion following trauma maybe directly related to the absence of nutrient arteries entering the bones.

\section{REFERENCES}

1. Ross MH. Bone. In: Lippincott Williams and Wilkins. (eds) Histology, a text and atlas. $7^{\text {th }}$ edi. Philadelphia: Wolters Kluwer 2015:218-23.

2. Sullivan FJE, Breathnach AS. Human skeleton. In: Breathnach AS (ed). Frazer's anatomy of Human Skeleton. $6^{\text {th }}$ edi. London: Churchill 1965:120-6.

3. Miller MD, Thompson S. Basic sciences, section 1: bone. In: Cosker T, Elsayed S. (eds) Review of orthopaedics. $5^{\text {th }}$ ed. Philadelphia: Saunders Elsevier 2012:5-6.

4. Branemark PI. Vital microscopy of bone marrow in rabbit. Scand J Clin Lab Invest 1959;11 Suppl 38:1-82.

5. Standring S. Gray's anatomy. Functional anatomy of the musculoskeletal system. $40^{\text {th }}$ ed. London, Elsevier Churchill Livingstone. Chapter 5, 2008:85-91.

6. Mysorekar VR. Diaphyseal nutrient foramina in human long bones. J Anat 1967;101(4):813-22.

7. Carroll SE. A study of the nutrient foramina of the humeral diaphysis. J Bone Joint Surg 1963;45:176-81.

8. Campos F, Pellico GL, Alias G, et al. A study of the nutrient foramina in human long bones. Surg Radiol Anat 1987;9:251-5.

9. Kizilkanat E, Boyan N, Ozsahin ET, et al. Location, number, and clinical significance of nutrient foramina in human long bones. Ann Anat 2007;189(1):87-95.

10. Longia GS, Ajmani ML, Saxena SK, et al. Study of diaphyseal nutrient foramina in human long bones. Acta Anat (Basel) 1980;107(4):399-406.

11. Shulman SS. Observations on the nutrient foramina of the human radius and ulna. Anat Rec 1959;134(4): 685-97. 